\title{
A Study on the Power Quality of DG Integrated Building Energy System in Virtual Environment
}

\author{
Shafiuzzaman K. Khadem \\ Technological University Dublin \\ Ruth Kerrigan \\ Integrated Environmental Solutions, Glasgow \\ Malabika Basu \\ Technological University Dublin, mbasu@tudublin.ie
}

See next page for additional authors

Follow this and additional works at: https://arrow.tudublin.ie/engscheleart

Part of the Electrical and Electronics Commons

\section{Recommended Citation}

Khadem, S.K.; Kerrigan, R.; Basu, M.; Basu, B., "A study on the power quality of DG integrated building energy system in Virtual Environment," Power Engineering Conference (UPEC), 2013 48th International Universities' , vol., no., pp.1,5, 2-5 Sept. 2013 doi: 10.1109/UPEC.2013.6715037

This Conference Paper is brought to you for free and open access by the School of Electrical and Electronic Engineering at ARROW@TU Dublin. It has been accepted for inclusion in Conference papers by an authorized administrator of ARROW@TU Dublin. For more information, please contact arrow.admin@tudublin.ie, aisling.coyne@tudublin.ie,gerard.connolly@tudublin.ie. Funder: Irish Research Council for Science, Engineering and Technology. Integrated Environmental Solutions under the Enterprise Partnership Scheme

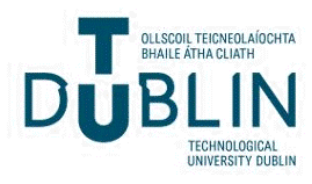




\section{Authors}

Shafiuzzaman K. Khadem, Ruth Kerrigan, Malabika Basu, and Biswajit Basu

This conference paper is available at ARROW@TU Dublin: https://arrow.tudublin.ie/engscheleart/213 


\section{A Study on the Power Quality of DG Integrated Building Energy System in Virtual Environment}

\author{
Shafiuzzaman K Khadem \\ Member IEEE \\ Dept of Civil, Structural \& \\ Environmental Engineering, \\ Trinity College, Ireland \\ E-mail:khademm@tcd.ie
}

\author{
Ruth Kerrigan \\ Integrated Environmental \\ Solutions, Glasgow, UK \\ E-mail: \\ ruth.kerrigan@iesve.com
}

\author{
Malabika Basu \\ Member IEEE \\ School of Electrical \& \\ Electronic Engineering, \\ Dublin Institute of \\ Technology, Ireland \\ E-mail: mbasu@ieee.ie
}

\author{
Biswajit Basu \\ Member IEEE \\ Dept of Civil, Structural \& \\ Environmental Engineering, \\ Trinity College, Ireland \\ E-mail: basub@tcd.ie
}

\begin{abstract}
In this paper, the electrical energy demand of a typical residential building has been extracted from a Virtual Environment (VE) simulation. The extracted energy demand is generated by input load demand and hourly operating information. Based on the electrical energy demand for a typical day, a building integrated photovoltaic (PV) system is then simulated in MATLAB to extract the current/voltage disturbance information into the network. Outcome of this simulation shows the voltage/current waveform along with the disturbances at different locations in the building. The city of Dublin, Ireland has been chosen as a geographical location and VE-Pro software has been used to develop the virtual environment simulation for the building energy system. The simulation based on VE-Pro and MATLAB indicates the scope for possible placement of Custom Power Devices (CPDs) to improve the power quality of the DG integrated building energy system.
\end{abstract}

Index Terms-- Building Energy Management System, Custom Power Devices, Virtual Environment, Power Quality, Distributed Generation, Micro-generation, Smart Grid

\section{INTRODUCTION}

Depending on location and resource availability, DG (Distributed Generation) like solar and wind energy systems are introduced in building energy management systems (BEMS) as a source of micro-generation. The micro-source favors the utility network (i) by reducing the GHG emission and power loss in the utility distribution system, and (ii) by saving utilized cost of energy based on REFIT (Renewable Energy Feed-in-Tariff) policy. On the contrary, DG converters can introduce current harmonics/ voltage disturbances at the PCC (Point of Common Coupling) [1] Grid-tie DG converters also seize to operate during the occurrence of voltage sag/swell at the utility side as per the EN50438 or IEEE 1547-2003 standard [2, 3].

Besides, the use of non-linear loads in building is also increasing and thus creates power quality disturbances by injecting harmonics to the grid. By nature, the energy available from renewable energy technology (RE) based DG systems is also variable. Therefore, in RET based energy micro-generation ( $\mu \mathrm{Gen}$ ) systems in buildings with non-linear loads, some control elements are necessary to overcome these voltage/current disturbances. Having the real-time information on energy supplies and forecast, availability of energy with desired power quality and load demand, the development of efficient and dynamic building energy management system is possible.

As a part of development of an efficient building energy management system (BEMS) and with a view to study the power quality at PCC, a PV based $\mu$ Gen system integrated with building energy management system has been developed in virtual environment (VE). The city of Dublin, Ireland has been chosen as a geographical location. VE-pro, one of the leading building energy management software for design and retrofit of HVAC (Heating Ventilation and Air Conditioning) system [4] has been chosen as a platform for the development of virtual environment simulation. Geo-resource information for the Dublin is also available in the VE-pro. Section II of this paper deals with a short description of the BEMS development in the virtual environment of VE-pro. As the current waveforms for different non-linear loads are not available in the VE-pro, to study the power quality issues, these have been collected from the existing literature and studies available on measurement. This has been discussed in section III. Extracting the hourly load profile from the VE-pro and the harmonic information of the frequently used nonlinear loads, an electrical model has been developed in MATLAB. Subsequently the performance of the integrated system is analysed for a typical day. Section IV describes details of this simulation study and the results. From this simulation, the deterioration of power quality in the DG integrated building energy system has been identified. Concluding remarks have been made in section V. CPDs (Custom Power Devices) like APF (Active Power Filter), DVR (Dynamic Voltage Restorer) and UPQC (Unified Power Quality Conditioner) can be placed at the PCC to overcome these power quality problems $[1,5-7]$.

\section{BEMS IN VIRTUAL ENVIRONMENT}

A brief description on the model development and simulation in VE-pro for BEMS is given here. VE-pro deals with load-by-load analysis starting from a single to multiroom in a building. Fig 1 shows a simple virtual model of a 
building/house developed in VE-pro. It precisely considers the building materials, construction, interior of the building, placement of components/appliances. It also accounts for the shading effect of nearby building/obstacles or the building itself. Based on the geo-position of the building, time series hourly weather information and the placement of thermal and electrical load/appliances in the building along with their operating hours, VE-pro then calculates the available and demanded thermal/electrical energy. Effect of weather information on day-night energy demand calculation can also be viewed in a 3D mode in the virtual environment, as shown in Fig 2. Thus, it articulates the thermal and electrical demand of energy more precisely.

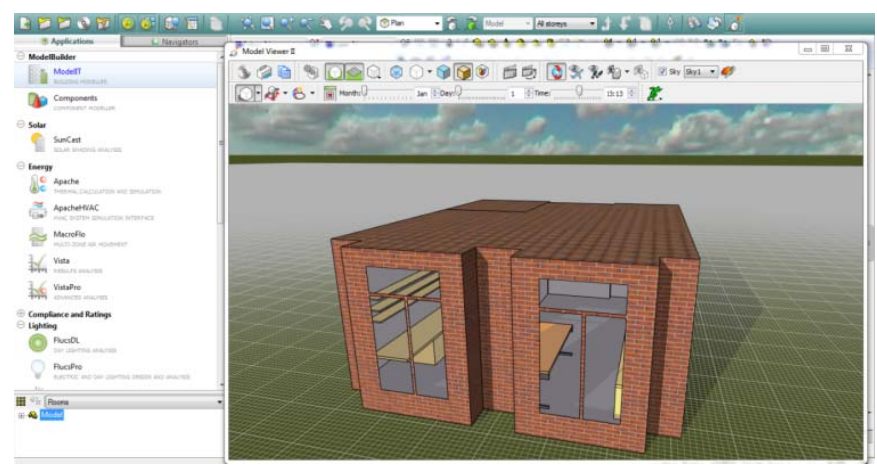

Fig 1: Virtual model of a building developed in VE-pro

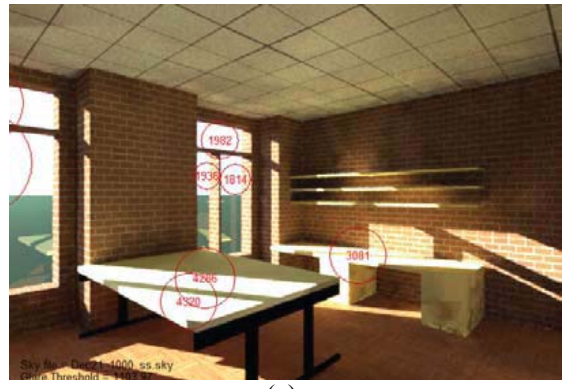

(a)

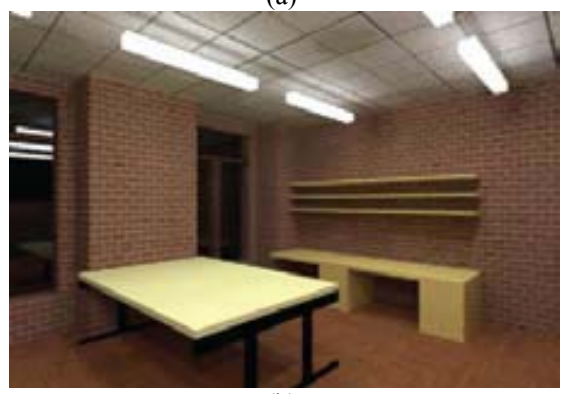

(b)

Fig 2: (a) Day and (b) night effect on energy demand viewed in a 3D mode

Utilization Energy demand can also be precisely optimized by improving the thermal comfort of the building and this can also be suggested by the VE-pro simulation. Based on the input information, the monthly average hourly available solar radiation in Dublin and the extracted load demand for a single user are shown in Fig 3. Solid lines represent the load demand (in $\mathrm{kW}$ ) for 4 typical months whereas the dashed lines show the available radiation (global horizontal irradiance - GHI) in
$\mathrm{kW}$ for the corresponding months. It also reflects that the hourly solar radiation is low or close to zero when the load demand is high. Again, the monthly average load demand is low in the summer months (Apr and Jul) whereas the energy availability from solar energy is high for the same period.

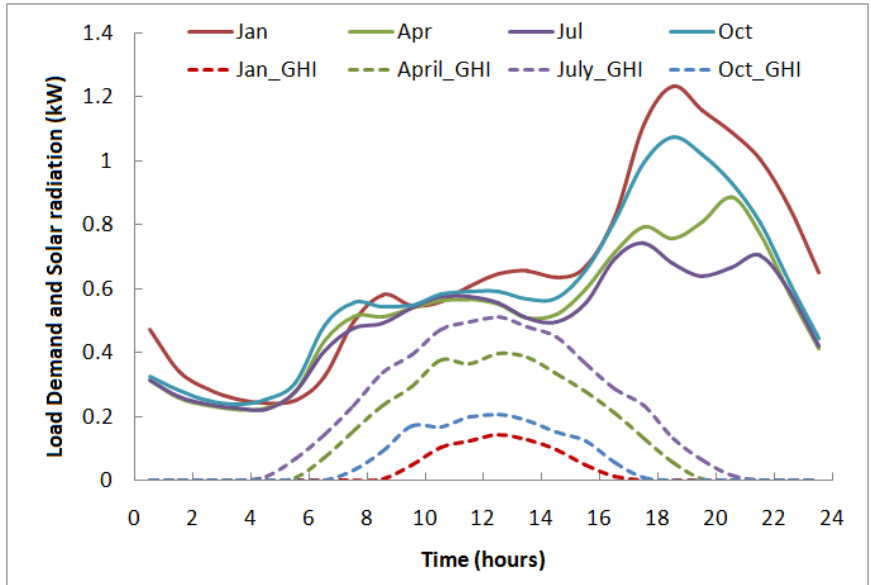

Fig 3: Monthly average hourly load demand for a single user and the available horizontal radiation in Dublin

\section{HARMONICS IN NON-LINEAR LOADS}

The term that is used to compute the harmonic pollution in electrical power signals is THD (Total Harmonic Distortion) and mathematically, it can be calculated as;

$T H D=\frac{\sqrt{\sum_{h=2,3,4 \ldots} I_{h}^{2}}}{\mathrm{I}_{\mathrm{pcc} f}}$

where $I$ is the rms value of current, the suffix $h$ denotes the harmonic contents where $h=2,3,4 \ldots .$. and $\mathrm{I}_{\mathrm{pcc} f}$ is rms value of the active fundamental current.

According to the IEEE Standard 519 and 1547 [3, 9], when the DG is connected, harmonic current injection (as a \% of THD) by the DG unit and the non-linear load at the PCC shall not exceed the limits, as given in Table 1.

TABLE1

MAXIMUM HARMONIC CURRENT DISTORTION [3, 11]

\begin{tabular}{|c|c|c|c|c|c|c|}
\hline $\begin{array}{c}\text { Individual } \\
\text { harmonic } \\
\text { order, } h\end{array}$ & $h<11$ & $11<h<17$ & $17<h<23$ & $23<h<35$ & $35 \leq h$ & THD \\
\hline $\begin{array}{c}\text { Percent } \\
(\%)\end{array}$ & 4.0 & 2.0 & 1.5 & 0.6 & 0.3 & 5.0 \\
\hline
\end{tabular}

Most of energy efficient home appliances such as CFL bulb, LCD/Plasma TV, PC/Laptop, microwave oven use switched mode power supply/uninterruptable power supply/rectifier etc to achieve the rectification phenomena and thus produce and inject harmonics to the grid [10-14]. Fig 4 shows the current waveforms and the FFT analysis for two of the most popular energy efficient appliances (CFL bulb and LCD TV). It reflects that the THD is very high for these appliances. The effect of these high THD finally reduces the 
efficiency of the distribution system by increasing the line and transformer losses [13, 14]. Sometimes, it can even damage the distribution transformer.

The total power consumed by an individual load can be calculated from its fundamental and harmonic components. This is also reflected in the power tetrahedron diagram [15], as shown in Fig 5. The components can be given as;

$$
\begin{aligned}
S & =P+j Q=\left(\bar{P}_{f}+\tilde{P}_{H}\right)+j\left(\bar{Q}_{f}+\tilde{Q}_{H}\right) \\
|S| & =\sqrt{P_{f}^{2}+Q_{f}^{2}+H^{2}}
\end{aligned}
$$

with, $H=\sqrt{P_{H}^{2}+Q_{H}^{2}}$

$S=$ Total power

$P=$ Active or real power

$Q=$ Reactive power

$H=$ Harmonic power

$f=$ fundamental component

$P_{H}=$ Harmonic component of active power

$Q_{H}=$ Harmonic component of reative power
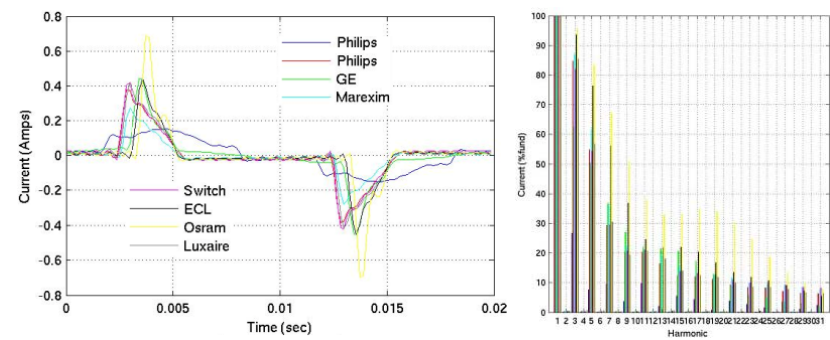

(a)
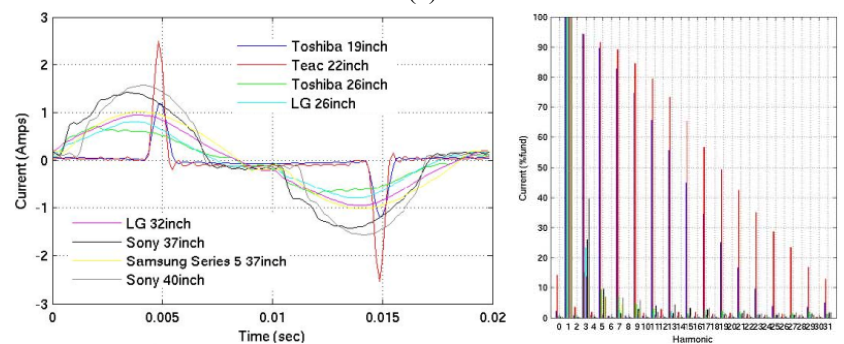

(b)

Fig 4: Current waveform and FFT analysis for (a) CFL and (b) LCD TV [12]

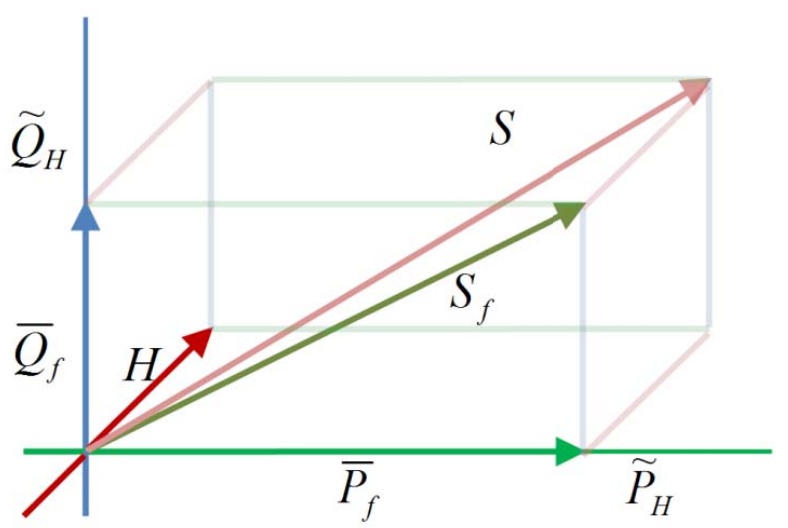

Fig 5: Power tetrahedron diagram

\section{Simulation Study and Results}

Fig 6(a) shows the PV $\mu$ Gen based BEMS system connected to the grid. Extracting the solar radiation, load profile information from the virtual environment (simulated VE-pro), and THD information for some of the non-linear loads as shown in Fig 6(a), the complete system has been modeled in MATLAB. The modeling of non-linear residential loads based on single phase diode-bridge converter is also described in [10]. In this paper the model has been derived from the available harmonic information ( $\%$ of THD). Fig 6(b) shows the complete system modelled in MATLAB.

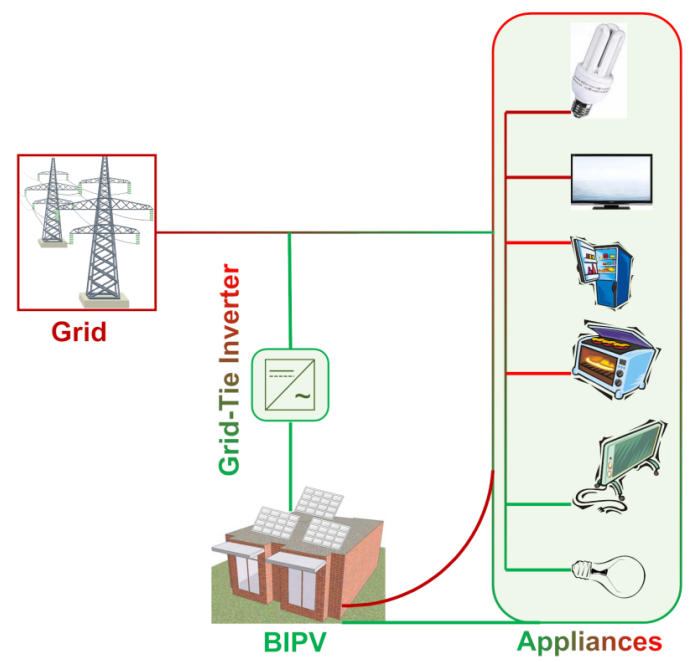

(a)

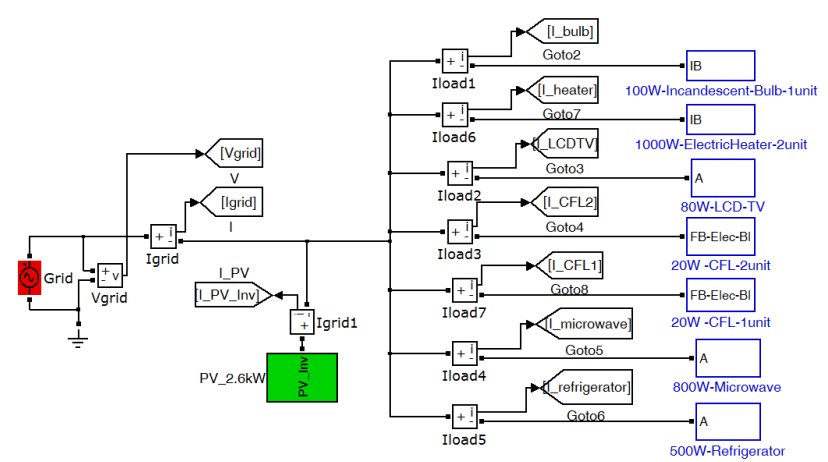

(b)

Fig 6: (a) PV integrated building energy system connected to the grid and (b) modeled in MATLAB

Fig 7 shows the simulation result for a typical day based on the load operating hours as given in Table 2. Fig 7(a) shows the active $(\mathrm{P})$, reactive $(\mathrm{Q})$, harmonic $(\mathrm{H})$ and total power $(\mathrm{S})$ of the system during the 24 hour operating condition. It shows that the harmonic power increases during the evening time when most of the harmonic loads like PC, TV, CFL bulbs are in operation. Thus, it increases the total power consumed by the system. Current waveforms and the related THD information are also obtained from the simulation, as shown in Fig 7(b). Current waveform at 6:00 am and at 7:00 pm is also zoomed out in Fig 7(b). Fig 7(c) and 7(d) show the 
respective harmonic orders for the selected zoomed out portion of the Fig 7(b).

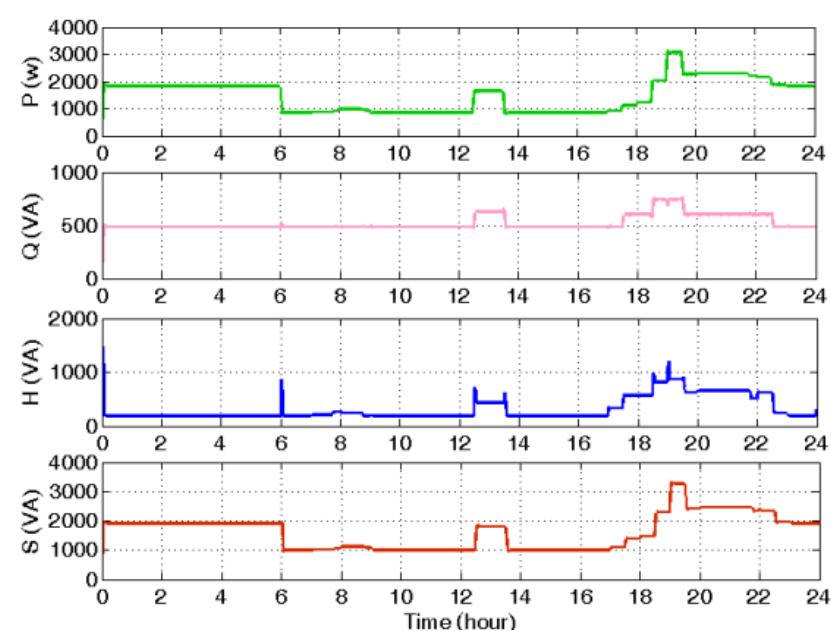

(a)
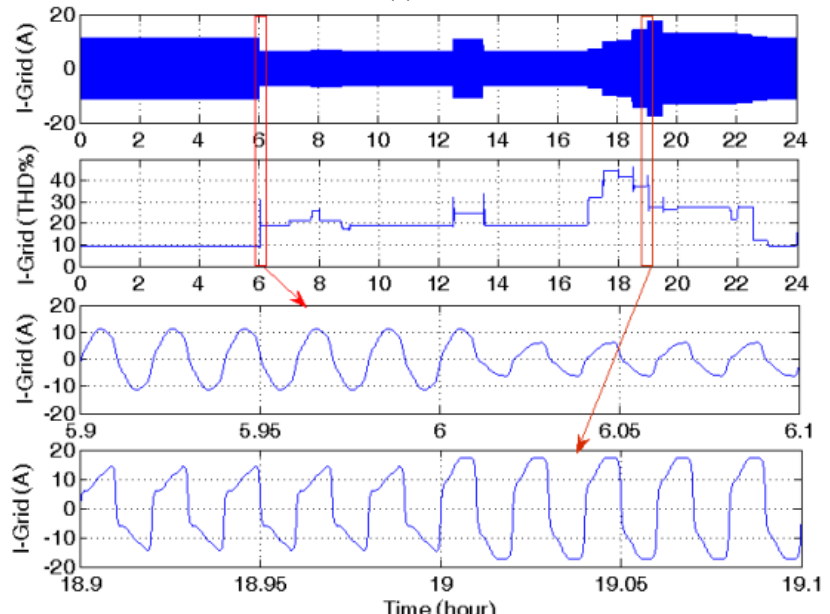

(b)

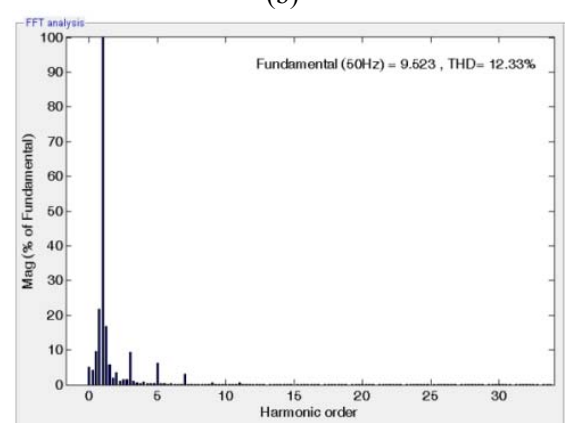

(c)

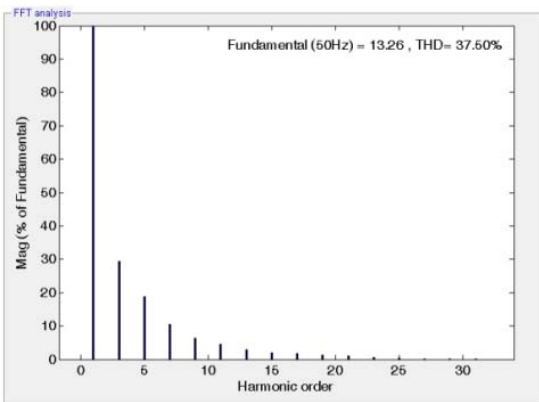

(d)

Fig 7: Power flow in a typical day without PV system
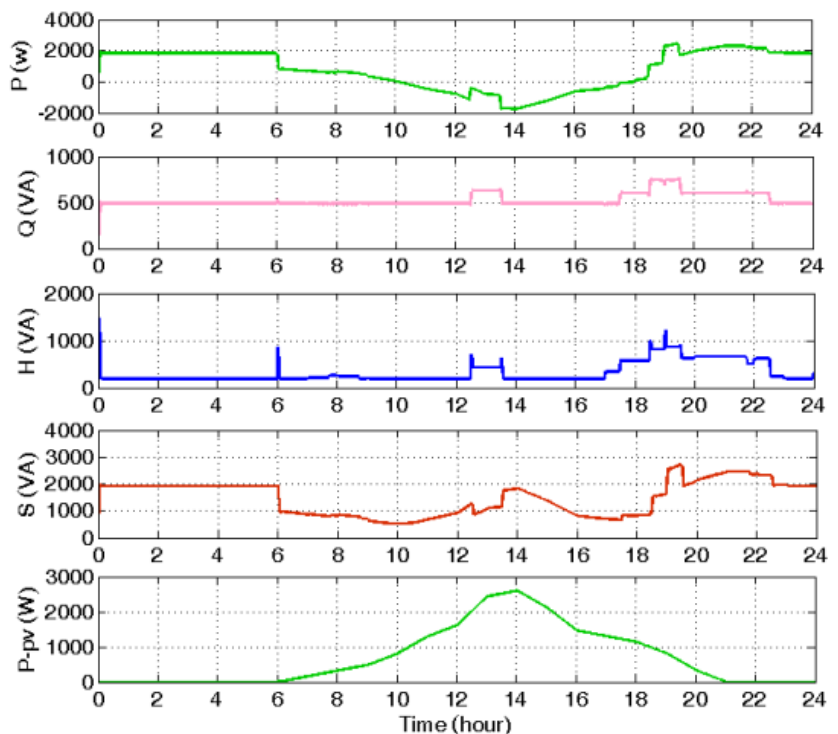

(a)

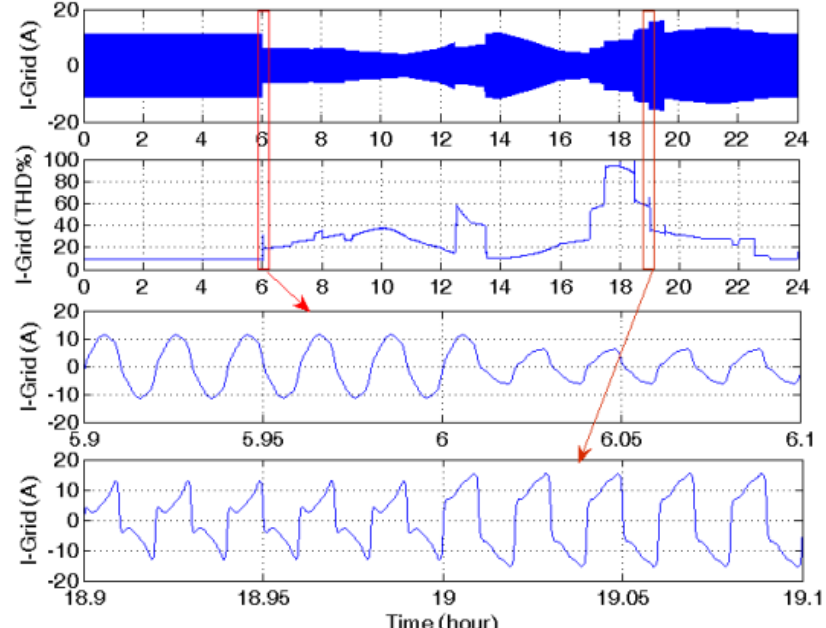

(b)

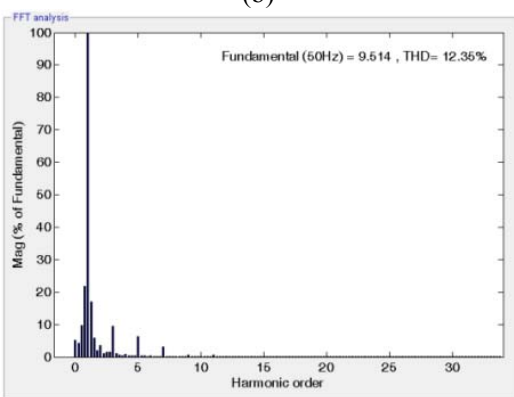

(c)

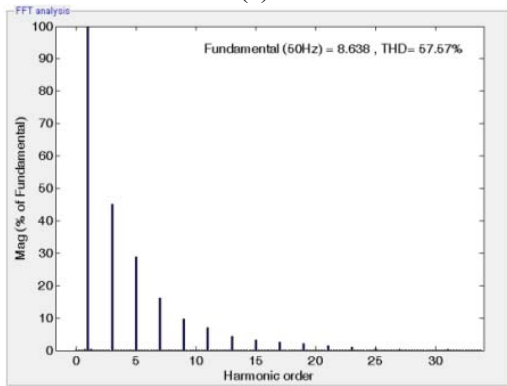

(d)

Fig 8: Power flow in a typical day with PV system 
TABLE2

LOAD OPERATING HOURS

\begin{tabular}{|c|c|c|c|c|c|c|c|c|c|c|c|c|c|c|c|}
\hline Load & Capacity & & & & & & & & Operati & ig time & & & & & \\
\hline & $(\mathrm{kW})$ & 0 & 2 & 4 & & 6 & 8 & 10 & 12 & 14 & 16 & 18 & 20 & 22 & 24 \\
\hline $\mathrm{CFL}$ & 20 & & & & & & & & & & & & & & \\
\hline Heater & 1000 & & & & & & & & & & & & & & \\
\hline TV & 80 & & & & & & & & & & & & & & \\
\hline Microwave & 800 & & & & & & & & & & & & & & \\
\hline Refrigerator & 500 & & & & & & & & & & & & & & \\
\hline PC & 150 & & & & & & & & & & & & & & \\
\hline
\end{tabular}

Similar results have been shown in Fig 8 when the $\mu$ Gen (PV) is operating. The negative value of active power (P) shown in Fig 8(a) indicates the reverse flow of power and it occurs when the power generated by the PV is higher than the load demand. The excess power is transferred to the grid. Fig 8(b) shows the current and harmonic waveforms during the same period of operation. When the PV power is available, the active power flow from the grid becomes low and therefore the grid current sensor senses a reduced fundamental current. Thus the calculated current THD becomes high (though the harmonic contents remain same) and this is reflected in Fig 8(c, d).

Simulation results as shown in Fig 7 and 8 indicate that some form of power quality improvement by the placement of active or passive filter in the network is essential. To improve the power quality of the network, research is now being carried out by Trinity College Dublin (TCD), Dublin Institute of Technology (DIT) and Integrated Environmental Solution (IES) on the integration of Custom Power Devices (CPDs) in the DG connected network. Because of the uncontrollable sources (PV/Wind) of generation in buildings, though the harmonic contents remain same, the calculated current THD at the PCC varies. Based on the simulation results and the harmonic information in the power flow of the individual loads, it is possible to suggest the placement of CPDs in the network. Some of the analyses have been done in [16] and it is found that the placement of feedback current sensors for the CPDs plays an important role for a stable control and operation of the devices.

\section{CONCLUSION}

This paper investigates the impact of integration of DG energy system on the power quality of buildings. The study is based on simulation on a VE platform using software VE-pro and MATLAB Simulink. It can be concluded from the results that there is an increase of undesirable harmonics injection into the network due to the building integrated renewables. This may cause damage in sensitive equipment, energy loss in the distribution line and failure of the distribution transformer. The study also shows that if DG sources are introduced as a micro power generation for the end user, the measured THD at PCC in the network is increased. Moreover, DG converter could introduce voltage disturbance in the network. To prevent this harmonic current injection by the non-linear loads as well as the voltage disturbance created by the DG converters, future studies should consider the integration of CPDs by network users and distributors.

\section{ACKNOWLEDGEMENTS}

The writers are grateful to the Irish Research Council for Science, Engineering and Technology (IRCSET) and Integrated Environmental Solutions (IES) for their financial support under the Enterprise Partnership Scheme (Grant No. G30589).

\section{REFERENCES}

[1] Khadem S K, Basu M and Conlon M F, Power Quality in Grid connected Renewable Energy Systems: Role of Custom Power Devices, ICREPQ, 2010

[2] Requirements for the connection of micro-generators in parallel with public low-voltage distribution networks, EN 50438, www.enstandard.eu

[3] IEEE 1547-2003 - IEEE Standard for Interconnecting Distributed Resources with Electric Power Systems

[4] VE-pro, Integrated Environmental Solutions, http://www.iesve.com/software/ve-pro

[5] Khadem S K, Basu M and Conlon M F, Parallel Operation of Inverters and Active Power Filters in Distributed Generation System - A Review, Sustainable and Renewable Energy Review, Vol. 15(9), 2011, pp. $5155-5168$

[6] Khadem S K, Basu M and Conlon M F, UPQC for Power Quality Improvement in DG Integrated Smart Grid Network - A Review, International Journal of Emerging Electrical Power Systems, Vol. 12(1), 2012, Art. 3

[7] Khadem, S K, Basu M, Conlon M F, Integration of UPQC for Power Quality improvement in distributed generation network - a review, ISGT-Europe, Vol. 1, 2011, pp.1-5

[8] Khadem, S.K.; Basu, M.; Conlon, M.F., A review of parallel operation of active power filters in the distributed generation system, EPE 2011, Vol. 1, 2011, pp.1-10

[9] IEEE-519: IEEE Recommended Practices and Requirements for Harmonic Control in Electric Power Systems, 1992

[10] Jing Y, Liang C, Shuangyan C, Modeling of Home Appliances for Power Distribution System Harmonic Analysis, IEEE Trans Power Delivery, vol.25, no.4, pp.3147-3155, Oct. 2010

[11] Koval, D.O.; Carter, C., Power quality characteristics of computer loads, Industry Applications, IEEE Transactions on , vol.33, no.3, pp.613,621, May/Jun 1997

[12] Hardie, S.; Watson, N., The effect of new residential appliances on Power Quality, Universities Power Engineering Conference (AUPEC), 2010 20th Australasian, vol., no., pp.1,6, 5-8 Dec. 2010

[13] Farooq H, Zhou C, Farrag M E, Analyzing the harmonic distortion in a distribution system caused by the non-linear residential loads, International Journal of Smart Grid and Clean Energy, Vol. 2(1), 2013, pp. 46-51

[14] Singh, R.; Singh, A., Energy loss due to harmonics in residential campus - A case study, UPEC, Vol. 1, 2010, pp.1-6

[15] H Akagi, E H Watanabe and M Aredes, Instantaneous Power Theory and Applications to Power Conditioning. Piscataway, NJ: IEEE Press, 2007

[16] Khadem S K, Power quality improvement of distributed generation integrated network using unified power quality conditioner, $\mathrm{PhD}$ Thesis, DIT, Ireland, 2013. 